\title{
EL ESPAÑOL DEL CARIBE: UNIDAD FRENTE A DIVERSIDAD DIALECTAL
}

\author{
Orlando Alba \\ Pontificia Universidad Católica Madre y Maestra \\ República Dominicana \\ Brigham Young University. Provo, Utah
}

0. Muchos investigadores consideran que las grandes Antillas españolas exhiben una notable homogeneidad lingüística que permite hablar con propiedad sobre "el español antillano" o "el español del Caribe" como una entidad dialectal única. Es revelador de esta concepción el hecho de que todos los intentos de zonificación dialectal realizados sobre el español en América coincidan en situar a las tres islas antillanas dentro de una misma zona que para algunos, incluso, es la más compacta y uniforme de todas. Así lo hizo en la primera mitad del siglo Pedro Henríquez Ureña, y todos los que con posterioridad han rectificado o refinado la división propuesta por el filólogo dominicano ${ }^{1}$.

Las descripciones dialectales no cuantitativas señalan como rasgos unificadores en el nivel fonético, por ejemplo, la tendencia radical del consonantismo posnuclear, ejemplificada principalmente con el desgaste de la /s/, la posteriorización de la $/ \mathrm{n} /$, y la neutralización de las líquidas $/ 1 / \mathrm{y} / \mathrm{r} /$. En el campo morfosintáctico se citan fenómenos como la presencia del pronom-

1 Véase, principalmente, P. Henriquez Urefía, «Observaciones sobre el español de Américaw, Revista de Filología Española, VIII, 1921, págs. 357-390. Entre los trabajos sobre el mismo asunto cabe citar, entre otros, los de José Pedro Rona, «El problema de la división del español americano en zonas dialectales», Presente y futuro de la lengua española, I, Madrid, Ediciones Cultura Hispánica, 1964, págs. 215-226; P. Cahuzac, «La división del español de América en zonas dialectales. Solución etnolingülstica o semánticodialectal», Lingüística Española Actual, II, 1980, págs. 385-461; J. Zamora Munné y J. Guitart, Dialectología Hispanoamericana. Teoria-Descripción-Historia, Salamanca, Ediciones Almar, 1982, págs. 177-184. 
bre antepuesto a infinitivos ("al yo salir") y al verbo en oraciones interrogativas ("¿cómo tú estás?"). Con respecto al léxico es constante la referencia al uso de arcaísmos, afronegrismos, indigenismos, anglicismos.

Esa convicción o impresión de uniformidad, sin embargo, contrasta con las creencias o las apreciaciones subjetivas de los propios hablantes caribeños (cubanos, dominicanos y puertorriqueños) para quienes sus respectivos dialectos son inconfundibles. Se sabe que no solo el hombre de la calle sino también los medios de comunicación (la televisión, la radio) a menudo utilizan con bastante eficacia una serie de fenómenos lingüísticos como indices caracterizadores o identificadores de los nativos de cada país ${ }^{2}$. Es normal, así, que un dominicano sea capaz de reconocer por su manera de hablar a un puertorriqueño o a un cubano, o, por lo menos, de identificarlos como no dominicanos. Lo mismo ocurre, naturalmente, en sentido inverso.

$\mathrm{La}$ discrepancia de visiones podria tener su explicación en variados factores. En tanto unos (lingüistas o investigadores), en su búsqueda de patrones y generalizaciones, con frecuencia se inclinan por poner el énfasis en las semejanzas, los otros (los usuarios, los hablantes) centran especialmente su atención en las diferencias, en lo individualizador.

Desde otra perspectiva, parecería que desde fuera el observador tiende a percibir la realidad en su conjunto, sin discriminar los detalles o los aspectos particulares. De ahí su percepción de homogeneidad o de unidad. En cambio, desde dentro, a los hablantes les resulta más fácil advertir las diferencias con las que tienen un contacto directo o inmediato.

Conviene recordar, como apunta López Morales, que desde el punto de vista teórico "las variedades diatópicas, los dialectos, no se diferencian demasiado de las lenguas, ya que son sistemas tan virtuales y $\tan$ irrealizables como aquéllas, aunque con contrastes menos marcados; tampoco disponen de hablantes reales... Hablar del español del Caribe, del antillano, del dominicano o del de la ciudad de Santo Domingo, conlleva una jerarquía de abstracciones; son identificaciones, conceptualizaciones, a las que sólo se puede llegar a través de ejercicios intelectuales, aunque éstos sean, por supuesto, de una utilidad extrema desde muchos puntos de vista: las sintopías, por minúsculas que sean, no garantizan la homogeneidad lingüística necesaria para hablar de 'auténticas' unidades" 3.

Parece legítimo plantear, en consecuencia, la disyuntiva sobre la unidad o la diversidad lingǘstica del Caribe hispánico. ¿Posee el Caribe hispánico

a Se trata, generalmente, de elementos léxicos y, sobre todo, fonéticos. Dentro de estos últimos suele jugar un papel muy importante la entonación. A pesar del carácter estereotipado de muchos de esos factores, parece claro que cumplen una función identificadora desde el punto de vista diatópico.

- H. López Morales, Sociolingüística, Madrid, Gredos, 1989, pág. 41. 
insular una verdadera unidad dialectal o coexisten en el interior de sus fronteras diferentes modalidades dialectales?

1. Hasta hace poco tiempo fueron notorios el aislamiento y la dispersión con que se desarrollaron los esfuerzos de la mayoria de los investigadores de la dialectologia del español americano, incluso dentro de una región $\tan$ pequeña como las Antillas. Tal situación, lógicamente, no solo ha dificultado sino que ha hecho imposibles o infructuosos los intentos de comparación de la realidad lingüistica de nuestros países. Simplemente no se ha creado una base de comparación segura, coherente y homogénea. Este estado de cosas ha llevado a Vaquero de Ramírez a referirse al "tradicional narcisismo practicado en cada una de las tres islas, donde nada se había hecho de la misma manera ni con los mismos propósitos; donde todo se había pensado como si la cercanía geográfica y los lazos compartidos durante cuatro siglos fueran meros accidentes" 4.

A partir de la década de los años 70 , sin embargo, la situación se presenta menos sombría. En la zona del Caribe han sido realizados varios trabajos con metodología similar ${ }^{5}$. Tales investigaciones de carácter cuantitativo permiten realizar un ensayo de comparación dialectal de las tres grandes Antillas tomando como base unos indices relativamente objetivos y homogéneos que arrojen luz sobre el estado real de la cuestión.

2. Cuando los estudios dialectales de conjunto destacan la unidad lingüística antillana, se apoyan en la consideración global de determinados hechos, como el debilitamiento consonántico o la presencia de elementos léxicos de origen marinero, indígena, africano. Suponen que tales procesos están presentes en las tres islas con la misma proporción y que el vocabulario arcaico, indigena, etc., está integrado por las mismas unidades.

Sin embargo, el análisis cuantitativo de diversos fenómenos revela diferencias lingüísticas importantes entre las tres Antillas. Si se comparan objetivamente los dialectos de Puerto Rico y República Dominicana, por ejemplo, se descubren divergencias en todos los niveles de análisis.

Desde el punto de vista fonético, existen distinciones cuantitativas que

- M. Vaquero de Ramírez, «El español de Puerto Rico en su contexto antillano», Conferencia plenaria lefda en el «III Congreso Internacional sobre el español de América», Universidad de Valladolid, España, julio de 1989, pág. 16.

5 En el surgimiento de esta nueva etapa de los estudios lingüísticos antillanos ha jugado un papel determinante la celebración a partir de 1976 de los simposios de Dialectologia del Caribe Hispánico, una iniciativa del doctor $\mathrm{H}$. López Morales. Hay que destacar en este sentido dos aspectos: 1. Puerto Rico ocupa una posición de vanguardia dentro de las Antillas en lo que a estudios cuantitativos se refiere; 2. Aunque se han realizado estudios sobre los diferentes niveles lingüisticos, no hay dudas de que el campo mejor y más insistentemente analizado ha sido el fonética-fonológico. 
se pueden ilustrar con los procesos de debilitamiento experimentados por las alveolares $/ \mathrm{s} / \mathrm{y} / \mathrm{r} /$. Los resultados obtenidos por las investigaciones de López Morales ${ }^{6}$ para San Juan de Puerto Rico y por Alba ${ }^{7}$ para Santiago de los Caballeros, revelan que el dialecto dominicano de Santiago exhibe unos porcentajes mucho más altos que el puertorriqueño de San Juan, según nos indican los cuadros 1 y 2 .

\section{CUndro \# 1}

Distribución de las variantes de / $\mathbf{s}$ / según la posición en los dialectos de San Juan (Puerto Rico) y de Santiago (República Dominicana).

\begin{tabular}{|c|c|c|c|c|}
\hline & \multicolumn{2}{|c|}{ San Juan (P. R.) } & \multicolumn{2}{|c|}{ Santiago (R. D.) } \\
\hline & inter. & final & inter. & final \\
\hline$\left[\begin{array}{llllllll}8 & \ldots & \ldots & \ldots & \ldots & \ldots & \ldots\end{array}\right.$ & $7.4 \%$ & $9.6 \%$ & $10 \%$ & $11 \%$ \\
\hline 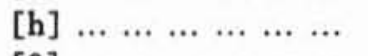 & 80.4 & 43.8 & 29 & 20 \\
\hline$\left[\begin{array}{llllllll}0 & \ldots & \ldots & \ldots & \ldots & \ldots & \ldots\end{array}\right.$ & 11.6 & 46.5 & 61 & 69 \\
\hline
\end{tabular}

\section{Cundro \#2}

Variantes de / $\mathrm{r} /$ en San Juan y Santiago.

\begin{tabular}{|c|c|c|}
\hline & San Juan (P. R.) & Santiago (R. D.) \\
\hline 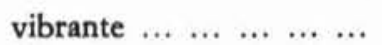 & $14 \%$ & $28 \%$ \\
\hline $\begin{array}{llllll}\text { fricativa } & \ldots & \ldots & \ldots & \ldots & \ldots\end{array}$ & 45.6 & 27 \\
\hline $\begin{array}{llllll}\text { lateral } & \ldots & \ldots & \ldots & \ldots & \ldots\end{array}$ & 34.6 & 5 \\
\hline $\begin{array}{llllll}\text { elidida } & \ldots & \ldots & \ldots & \ldots & \ldots\end{array}$ & 5.6 & 28 \\
\hline $\begin{array}{llllll}\text { vocalizada } & \ldots & \ldots & \ldots & \ldots\end{array}$ & - & 12 \\
\hline
\end{tabular}

El cuadro \# 1 muestra que en posición interna de palabra, por ejemplo, la elisión de la /s/ implosiva es cinco veces más frecuente en Santiago que en San Juan (61 \% vs. $11.6 \%$ ). La misma proporción se reproduce globalmente con la $/ \mathrm{r} /$ que es elidida con una frecuencia de $28 \%$ en Santiago y de solo $5.6 \%$ en San Juan, según revela el cuadro \# 2 .

También existen distinciones fonéticas cualitativas. Entre otras puede citarse la velarización de $/ \mathrm{rr} /$ presente en el dialecto sanjuanero de Puerto

- H. López Morales, Estratificación social del español de San Juan de Puerto Rico, México, Universidad Nacional Autónoma de México, 1983, págs. 42 y 81.

7 O. Alba, Variación fonética y diversidad social en el español dominicano de Santiago, Santiago, Pontificia Universidad Católica Madre y Maestra, 1990, págs. 77 y 163. 
Rico $^{8}$ con una frecuencia de $14.1 \%$ y totalmente ausente en República Dominicana. Inversamente, la vocalización de $/ \mathrm{r} /$ y $/ \mathrm{l} /$ implosivas sobrepasa el $40 \%$ en el sociolecto bajo de Santiago ${ }^{9}$ y es desconocida por los sociolectos de San Juan.

En el plano sintáctico basta pensar en una serie de estructuras anglicadas, como las de infinitivo y de gerundio, que presenta el español puertorriqueño como consecuencia de su especial situación de lengua en contacto con el inglés ${ }^{10}$.

En cuanto al léxico es previsible que las diferencias sean mayores. Hace veinte años Rosenblat se refería a la situación general del español en América con estas palabras: "Más afectan a la unidad las diferencias de léxico, a veces espectaculares" ". Por su parte, Lope Blanch observa que México podría dividirse en 17 regiones dialectales desde el punto de vista léxico ${ }^{12}$.

No obstante, el primer estudio léxico comparativo de las Antillas realizado sobre las denominaciones relativas al cuerpo humano parece apoyar la idea de la homogeneidad ${ }^{13}$. El análisis de López Morales arrojó como resultado que el $91.2 \%$ de las entradas del cuestionario ofrecen lexemas comunes a San Juan, Santiago de los Caballeros y La Habana. Solo el $5.1 \%$ obtuvo respuestas totalmente discrepantes.

El propio autor advierte, sin embargo, que las encuestas fueron respondidas por informantes de sociolecto alto y que se trata de un campo semántico (el cuerpo humano) poco propicio a la variación. Subraya, además, que "todo este léxico común es de procedencia patrimonial hispánica" ${ }^{14}$.

Con el objeto de conocer mejor a cuánto llega nuestro léxico compartido en otras parcelas léxicas, en el presente estudio se realiza una comparación de las tres grandes Antillas tomando como base los indices de mortandad ${ }^{15}$

8 Véase López Morales, op. cit., pág. 139.

- Véase Alba, op. cit., págs. 172 y 189.

10 Sobre estos asuntos pueden consultarse los trabajos de A. Morales, reunidos en su libro Gramáticas en contacto: análisis sintácticos sobre el español de Puerto Rico, Madrid, Editorial Playor, 1986.

11 A. Rosenblat, El castellano de España y el castellano de América. Unidad y diferenciación, Madrid, Taurus Ediciones, 1973, pág. 41.

12 J. Lope Blanch, «Henríquez Ureña y la delimitación de las zonas dialectales de Hispanoaméricas, en Cuadernos de la Facultad de Humanidades de la Universidad de Puerto Rico, 13, 1985, pág. 44.

1s Véase H. López Morales, «Muestra de léxico panantillano: el cuerpo humano», incluido en su libro Investigaciones léxicas sobre el español antillano, Santiago, Pontificia Universidad Católica Madre y Maestra, 1991, págs. 45-80.

14 Op. cit., pág. 80.

15 En la bibliografía lingüística reciente, la designación «mortandad léxica» alude a hechos diversos. Uno de ellos consiste en la pérdida o en la reducción, por diversas razones, de algunos de los elementos del inventario léxico empleado por una comunidad de habla. 
experimentados por los indigenismos y los afronegrismos. Para ello se utilizan los trabajos de Vaquero de Ramirez ${ }^{16}$ sobre el léxico indigena en Puerto Rico, López Morales ${ }^{17}$ sobre afronegrismos e indigenismos en Cuba, López Morales ${ }^{18}$ sobre la mortandad de los afronegrismos en Puerto Rico y Alba ${ }^{19}$ sobre indigenismos y afronegrismos, respectivamente, en Santiago de los Caballeros. Estos trabajos han contribuido a poner en claro qué unidades léxicas de origen indigena o africano tienen vigencia y cuáles, en cambio, pertenecen ya al pasado. Es lamentable que durante tanto tiempo la mayoria de los lexicógrafos hayan puesto su afán en resaltar el volumen de la aportación aborigen, africana, etc. Abundan, de esa manera, los estudios donde se incluyen extensos recuentos de elementos léxicos sin tomar en cuenta para nada su vitalidad. Junto a palabras efectivamente usadas por la comunidad aparecen decenas de fósiles o cadáveres léxicos, términos completamente desconocidos por la mayoría e incluso por la totalidad de los habitantes del pais, presentando asi una imagen deformada y falsa de la realidad.

\section{INDIGENISMOS}

El análisis de los resultados de las citadas investigaciones de López Morales, Vaquero y Alba nos revela un singular paralelismo cuantitativo entre las tres islas con respecto a los indigenismos pertenecientes a sus respectivas normas lingüisticas.

El cuadro 3 muestra las cifras correspondientes a los indigenismos conocidos, vivos o vigentes en el español puertorriqueño, dominicano y cubano. En términos relativos o porcentuales se aprecia una diferencia de $14 \%$ favorable a Puerto Rico con respecto a la República Dominicana, lo que lleva

16 M. Vaquero de Ramírez, «El léxico indígena en el español hablado en Puerto Ricow, en Léxico marinero de Puerto Rico y otros estudios, Madrid, Editorial Playor, págs. 127-148.

17 H. López Morales, «Indigenismos en el español de Cuba» y «Elementos africanos en el espańol de Cuba», en Estudios sobre el español de Cuba, New York, Las Américas Publishing Company, 1971, págs. 50-61 y 62-71, respectivamente.

18 Véase el estudio «Indices de mortandad léxica en Puerto Rico: afronegrismos», recogido en su libro ya citado Investigaciones léxicas sobre el español antillano, págs. 179-196.

10 O. Alba, «Indigenismos en el español hablado en Santiago», Anuario de Letras, XIV, 1976, págs. 71-100 y «Mortandad Lexica en el Caribe Hispánico: ensayo de comparación dialectal $\%$, ponencia lefda en el 1st. International Conference on Spanish in Contact with Other Languages, University of Southern California, Los Ángeles, 7-9 de noviembre de 1991 . 
a pensar que el índice de mortandad ha sido mayor en el español dominicano que en el puertorriqueño ${ }^{20}$.

\section{Cundro 3}

Indigenismos pertenecientes a la norma hablada en el Caribe Hispánico.

\begin{tabular}{|c|c|c|c|}
\hline & $\begin{array}{l}\text { \# de entradas en } \\
\text { el inventario base }\end{array}$ & $\begin{array}{l}\text { \# de entradas } \\
\text { pertenecientes a la norma }\end{array}$ & \% \\
\hline Puerto Rico $\ldots \ldots \ldots$ & 183 & 97 & 53.01 \\
\hline República Dominicana ... & 293 & 107 & 36.64 \\
\hline $\begin{array}{llllllll}\text { Cuba } & \ldots & \ldots & \ldots & \ldots & \ldots & \ldots\end{array}$ & - & 97 & - \\
\hline
\end{tabular}

Conviene recordar, sin embargo, que las fuentes utilizadas por la mayoria de los diccionaristas de indigenismos fueron básicamente bibliográficas. Por tal razón, es altamente probable que algunas de las unidades del inventario base nunca hayan formado parte de la norma lingüistica caribeña. En ese caso no se puede hablar, lógicamente, de mortandad como tal desde el punto de vista sincrónico, ya que, como afirma López Morales con respecto a los afronegrismos, dichas palabras "habían muerto antes de que ellos [los hablantes] entraran en la escena lingüística" ${ }^{21}$.

Las cantidades absolutas son notablemente similares para las tres Antillas: 97 elementos léxicos indígenas forman parte de la norma del español puertorriqueño y del cubano, mientras que 107 pertenecen a la norma dominicana.

Esta semejanza, sin embargo, es puramente numérica. Cuando se observan las unidades que componen esos inventarios léxicos, se descubre la presencia de numerosas diferencias.

Del centenar de términos que integran el componente léxico indigena vigente en el Caribe, solo 28 son comunes a la norma panantillana, es decir, el $28 \%$.

20 López Morales no ofrece la cifra total de indigenismos que componfan su inventario base, por lo que no es posible conocer sus resultados en porcentajes. Es oportuno sefialar, además, que aunque la metodología empleada por los tres autores citados es muy similar, el corpus que sirvió de base para la elaboración de los cuestionarios respectivos no es completamente uniforme.

21 H. López Morales, «Indices de mortandad léxica en Puerto Rico: afronegrismos», en Investigaciones léxicas sobre el español antillano, pág. 186. 


\section{Cundro 4}

Indigenismos comunes a las tres Antillas.

\begin{tabular}{lll}
\hline 1. aguacate & 11. carey & 21. huracán \\
2. aji & 12. cazabe & 22. iguana \\
3. barbacoa & 13. cocuyo & 23. jaiba \\
4. batey & 14. comején & 24. jicotea \\
5. bejuco & 15. enagua & 25. macana \\
6. bohí & 16. guano & 26. maíz \\
7. cacao & 17. guayaba & 27. maraca \\
8. caimito & 18. guayo & 28. sabana \\
9. canoa & 19. guira &
\end{tabular}

Otros elementos del inventario solo son compartidos por dos de los dialectos del Caribe. En ese sentido, el cuadro 5 revela un mayor parentesco entre Cuba y República Dominicana, que comparten 26 palabras, que entre Puerto Rico y República Dominicana, que solo coinciden en el uso de 13 indigenismos. Cuba y Puerto Rico, por su parte, apenas comparten 10.

\section{Cundro 5}

Indigenismos comunes a dos de las Antillas.

\begin{tabular}{|c|c|c|c|}
\hline P. Rico - R. Dom. & P. Rico - Cuba & \multicolumn{2}{|c|}{ Cuba - R. Dominicana } \\
\hline 1. arepa & 1. cacique & 1. anón & 14. jíbaro \\
\hline 2. cabuya & 2. guacamayo & 2. bija & 15. jícara \\
\hline 3. coa & 3. guasa & 3. butaca & 16. loro \\
\hline 4. conuco & 4. maguey & 4. caimán & 17. mamey \\
\hline 5. guaraguao & 5. manati & 5. catibía & 18. manf \\
\hline 6. guiro & 6. mangle & 6. ceiba & 19. papa \\
\hline 7. jagua & 7. manigua & 7. chicle & 20. tiburón \\
\hline 8. mabl & 8. papaya & 8. chocolate & 21. tiza \\
\hline 9. mime & 9. petaca & 9. guácima & 22. tomate \\
\hline 10. nigua & 10. piragua & 10. guanábana & 23. tuna \\
\hline 11. กิара & & 11. henequén & 24. yagua \\
\hline 12. pajuil & & 12. jaba & 25. yuca \\
\hline 13. yautía & & 13. jején & 26. zapote \\
\hline
\end{tabular}

El resto de los indigenismos, la mayoría, constituye un elemento diferenciador de los dialectos del Caribe, estableciendo entre ellos distinciones de carácter cualitativo, ya no simplemente cuantitativas. Por tratarse no de una alteración numérica en el inventario, sino de que estos están constituidos por 
unidades diferentes, su valor o su poder de discriminación es aún más fuerte. Dichas palabras se convierten en fenómenos síntoma, reveladores en este caso de la procedencia geográfica del hablante ${ }^{22}$.

\section{Cundro 6}

Indigenismos exclusivos de cada país ${ }^{23}$.

\begin{tabular}{|c|c|c|c|c|}
\hline \multirow{2}{*}{$\begin{aligned} \text { Cuba } \\
\text { 1. aura }\end{aligned}$} & Puerto Rico & \multicolumn{3}{|c|}{ Cuba - R. Dominicana } \\
\hline & 1. achiote & 1. & anamú ${ }^{*}$ & 32. totuma \\
\hline 2. bajareque & 2. atol & 2. & apasote & 33. tuatúa \\
\hline 3. caguama & 3. bayoya & 3. & auyama & 34. túbano \\
\hline 4. cayo & 4. bruquena & 4. & baitoa & 35. yaguacil \\
\hline 5. ciguato & 5. capá & 5. & batata & 36. yaguasa \\
\hline 6. colibri & 6. carrucho & 6. & cajuil & \\
\hline 7. curiel & 7. cemí & 7. & cancha & \\
\hline 8. cusubé & 8. cobo & 8. & cayuco & \\
\hline 9. chapapote & 9. cocolfa & 9. & caribe & \\
\hline 10. chirimoya & 10. cohítre & 10. & carite & \\
\hline 11. guacamole & 11. corozo & 11. & cigua & \\
\hline 12. guajiro & 12. curricán & 12. & ciguapa & \\
\hline 13. guanajo & 13. dita & 13. & cupey & \\
\hline 14. guao & 14. grayumo & 14. & $\operatorname{cur} 1(0)$ & \\
\hline 15. guataca & 15. guabá & 15. & cuyaya & \\
\hline 16. guateque & 16. guabina & 16. & chichigua & \\
\hline 17. guin & 17. guajana & 17. & guacal & \\
\hline 18. jaguey & 18. guanime & 18. & guama & \\
\hline 19. jarana & 19. guares & 19. & guatapaná & \\
\hline 20. jutía & 20. guícharo & 20. & guayacán & \\
\hline 21. majagua & 21. guímo & 21. & guazábara & \\
\hline 22. marañón & 22. jataca & 22. & higuera & \\
\hline 23. mariguano & 23. jojoto* & 23. & higuero & \\
\hline 24. morrocoyo & 24. juey & 24. & jobo & \\
\hline 25. papalote & 25. marrayo & 25. & lambi & \\
\hline 26. pita & 26. múcaro & 26. & locrio & \\
\hline 27. sicote $^{\star}$ & 27. petate & 27. & mapuey & \\
\hline 28. sinsonte & 28. quenepa & 28. & maya & \\
\hline \multirow{3}{*}{ 29. tamal } & 29. tabonuco & 29. & mico & \\
\hline & 30. yagrumo & 30. & patilla & \\
\hline & & 31. & tayota & \\
\hline
\end{tabular}

22 El tema de las distinciones cuantitativas vs. las cualitativas es uno de los más fecundos de la sociolingǘstica en su capítulo dedicado a la estratificación social de las lenguas. Lamentablemente, es un asunto poco explorado en las investigaciones sobre el español del Caribe.

23 El inventario base utilizado para la República Dominicana estuvo constituido exclusivamente por el material reunido por P. Henríquez Ureña, El español en Santo Do. 
Resulta interesante observar, a propósito de los datos recogidos en el cuadro 6, la vigencia en una de las tres islas de algunos indigenismos que en otra ya no tienen vida en la norma general de la comunidad y viceversa. Así, la norma dominicana conoce, entre otras, cajuil, chichigua, guacal, totuma, términos que han salido de la circulación general en Puerto Rico. Al revés vale decir de achiote, bruquena, guabina, yagrumo y otras más.

\section{Afronegrismos}

Muchos de los autores que se han interesado por el tema de la influencia africana en el español del Caribe compiten en reunir el mayor número posible de palabras sin atender a su vigencia y sin comprobar suficientemente su real procedencia etimológica ${ }^{24}$.

El primer estudio sobre la vigencia de los elementos africanos en el ámbito antillano fue publicado en 1971 con respecto al español de Cuba por López Morales. Dos décadas más tarde, el mismo investigador escribe sobre la mortandad de los afronegrismos en Puerto Rico. Sus datos son tomados como base de comparación con los resultados de un estudio similar que sobre el tema realicé recientemente en la ciudad de Santiago de los Caballeros, República Dominicana.

Una primera ojeada a los resultados generales de esas investigaciones permite apreciar que la presencia africana en el léxico antillano es mucho

mingo, Buenos Aires, Biblioteca de Dialectología Hispanoamericana, V, 1940, págs. 119. 129. Por este motivo no inclufa las palabras sicote ni jojoto, que aparecen como exclusivas de Cuba y Puerto Rico, respectivamente, y que son conocidas también en mayor o menor medida en la República Dominicana. Esa es, asimismo, la razón por la que aparece en esta lista de indigenismos la palabra anamú, que figura como afronegrismo en la nómina de Puerto Rico.

24 Esto se descubre, en mayor o menor grado, en los trabajos de F. Ortiz, Un cantauro de cubanismos. Apuntes lexicográficos, La Habana, 1924, para Cuba; M. Alvarez Nazario, El elemento afronegroide en el español de Puerto Rico, San Juan, Instituto de Cultura Puertorriqueña, 1974, y W. Megenney, «Sub-Saharan influences in the lexicon of Puerto Rico", Orbis, 30, 1983, págs. 214-260, para Puerto Rico; E. Deive, «Glosario de afronegrismos en la toponimia y español hablado en Santo Domingo», Aula, 2 (6-7), 1973, págs. 85-113, C. Larrazábal Blanco, «Vocabulario de afronegrismos», Boletín de la Academia Dominicana de la Lengua, II (4), 1941, págs. 54-78, y más recientemente W. Megenney, Africa en Santo Domingo: su berencia lingüistica, Santo Domingo, Editorial Tiempo, 1990, para la República Dominicana. A veces da la impresión de que algunos recopiladores de afronegrismos han partido del supuesto, naturalmente falso, de que las meras coincidencias o semejanzas fonéticas son prueba suficiente de filiación etimológica. Dada la naturaleza de este estudio, las unidades léxicas son tomadas directamente de los autores sin discutir el problema etimológico. Varios casos incluidos en las nóminas aquí manejadas ofrecen dudas a los especialistas y muy bien podría tratarse de indigenismos o incluso de hispanismos. 
menos visible que la indigena, tanto en términos absolutos como relativos. El porcentaje de elementos pertenecientes a la norma nos manifiesta que el índice de mortandad en el caso de los afronegrismos ha sido más elevado que en el de los indigenismos.

\section{CUAdRo 7}

Afronegrismos pertenecientes a la norma hablada en el Caribe Hispánico.

\begin{tabular}{|c|c|c|c|}
\hline & $\begin{array}{l}\text { \# de entradas en } \\
\text { el inventario base }\end{array}$ & $\begin{array}{c}\text { \# de entradas } \\
\text { pertenecientes a la norma }\end{array}$ & $\%$ \\
\hline $\begin{array}{l}\text { Puerto Rico } \ldots \ldots \ldots \\
\ldots\end{array}$ & 131 & 35 & 27 \\
\hline República Dominicana ... & 171 & 52 & 30 \\
\hline $\begin{array}{llllllll}\text { Cuba } & \ldots & \ldots & \ldots & \ldots & \ldots & \ldots\end{array}$ & - & 40 & - \\
\hline
\end{tabular}

En ninguno de los tres dialectos el número de afronegrismos alcanza siquiera la mitad de la cantidad de indigenismos integrantes de las normas respectivas. El cuadro 7 nos permite concluir que la inmensa mayoría de las palabras incluidas en los recuentos de afronegrismos ya no pertenecen al vocabulario utilizado en el Caribe. Muchas de ellas tienen frecuencia 0, es decir, no fueron conocidas por ninguno de los informantes de la muestra. Tal es el caso de calindá, candungué, cua, cunyá, danuá, macuenco, marindá, matungo, miñana, yubá.

En el dialecto dominicano de Santiago, que según el cuadro 7 muestra un indice de vigencia ligeramente más alto que los demás, hay que tomar en consideración que ocho de esas 52 palabras conocidas por más del $60 \%$ de los informantes, presentan un nivel de uso inferior al $60 \%$. Tales palabras, en consecuencia, solo pertenecen a la competencia pasiva de los hablantes, lo que las sitúa a medio camino en el proceso hacia la muerte léxica. Se trata de los términos añingotarse (ponerse en cuclillas), bongó (nombre de tambora), burundanga (conjunto de cosas inútiles, sin valor), chininingo (muy pequeño), mandinga (tipo de negro africano; cosa en mal estado); ñáñara (llaga), taita (papá, padre) y vodú (baile ritual). Esos mismos elementos léxicos, junto a desmandingarse (desbaratarse), macaco (mono; muchacho; persona fea), marimba (instrumento musical), motete (lío, paquete), quimbamba (lugar lejano e impreciso) y tutú (cabeza, cerebro), muestran una frecuencia muy inferior entre los jóvenes que entre los mayores de cincuenta años. Es un hecho que reafirma o denuncia su tendencia hacia la caducidad o la mortandad léxica.

Si se analizan ahora las unidades léxicas específicas que integran las nó- 
minas de las tres islas, se comprueba que solo seis constituyen la norma panantillana, según nos indica el cuadro 8 .

\section{Cundro 8}

Afronegrismos panantillanos.

\begin{tabular}{l} 
1. bachata \\
2. bembe(a) \\
3. bongo \\
4. guinea \\
5. mambo \\
6. ñame \\
\hline
\end{tabular}

Otros afronegrismos son comunes a dos de las Antillas. En este caso existe mayor afinidad entre Puerto Rico y República Dominicana que entre Cuba y República Dominicana, como sucedia con los indigenismos. Los dos primeros comparten 14 unidades, los segundos ocho y Cuba y Puerto Rico apenas dos. El cuadro 9 ofrece esos resultados.

\section{Cundro 9}

Afronegrismos comunes a dos de las Antillas.

\begin{tabular}{|c|c|c|}
\hline P. Rico - R. Dom. & R. Dom. - Cuba & Cuba - P. Rico \\
\hline $\begin{array}{l}\text { 1. abombarse } \\
\text { 2. añingotarse } \\
\text { (ñangotarse) } \\
\text { 3. chachachá } \\
\text { 4. chévere } \\
\text { 5. dengue } \\
\text { 6. gandul } \\
\text { (guandul) } \\
\text { 7. guarapo } \\
\text { 8. guineo } \\
\text { 9. malagueta } \\
\text { 10. merengue } \\
\text { 11. mofongo } \\
\text { 12. motete } \\
\text { 13. samba } \\
\text { 14. tostón }\end{array}$ & $\begin{array}{l}\text { 1. banana } \\
\text { 2. cachimbo } \\
\text { 3. conga } \\
\text { 4. champola } \\
\text { 5. chimpancé } \\
\text { 6. macaco } \\
\text { 7. ñáñara } \\
\text { 8. quimbamba }\end{array}$ & $\begin{array}{l}\text { 1. malanga } \\
\text { 2. quimbombó } \\
\text { (quingombó) }\end{array}$ \\
\hline
\end{tabular}

Todos los demás elementos léxicos de la norma son exclusivos de cada país. Se puede afirmar, en consecuencia, que el afronegrismo actúa más como 
Cundro 10

Porcentaje de afronegrismos panantillanos y exclusivos de cada país.

\begin{tabular}{|c|c|c|c|}
\hline & $\begin{array}{c}\text { \# de unidades } \\
\text { en la norma }\end{array}$ & $\begin{array}{l}\% \text { de unidades } \\
\text { panantillanas }\end{array}$ & $\begin{array}{l}\text { \% de unidades } \\
\text { exclusivas }\end{array}$ \\
\hline $\begin{array}{llllllll}\text { Cuba } & \ldots & \ldots & \ldots & \ldots & \ldots & \ldots & \ldots\end{array}$ & 40 & 15.00 & 60.00 \\
\hline República Dominicana $\ldots \ldots$ & 52 & 11.53 & 46.15 \\
\hline $\begin{array}{llllll}\text { Puerto Rico } & \ldots & \ldots & \ldots & \ldots & \ldots\end{array}$ & 35 & 17.14 & 31.42 \\
\hline
\end{tabular}

un factor fraccionador que como un lazo unificador desde el punto de vista dialectal en el Caribe Hispánico. Este hecho es particularmente notable en el caso del español cubano que emplea con exclusividad el $60 \%$ de sus afronegrismos. En una situación intermedia se encuentra la República Dominicana con un $46 \%$ de términos privativos y finalmente está Puerto Rico con un $31 \%$. El cuadro 10 nos entrega esos resultados.

$\mathrm{Al}$ igual que con los indigenismos, procede destacar el hecho de que algunos afronegrismos vigentes en un país han desaparecido o están en vías de hacerlo en otro, y a la inversa. Asi sucede con biyaya, cheche, fufú, jelengue, jubo, ñinga, sanaco, yaya, entre otros, vivos en Cuba pero ajenos a la norma general puertorriqueña o dominicana. Lo mismo puede decirse de Puerto Rico con respecto a las palabras cocolia, chango, funche, gongoli, monga. En República Dominicana, a su vez, perviven burundanga, can, cocolo, fucú, mangú, ñeñeñé, ñeco, entre otras.

La enumeración de todas esas unidades distintivas la ofrece el cuadro 11.

3. En conclusión, los análisis cuantitativos disponibles permiten observar que la zona del Caribe hispánico insular no presenta la homogeneidad lingüistica necesaria para ser considerada como entidad dialectal única. En esa dirección apuntan numerosos fenómenos en los diferentes niveles de análisis lingüistico.

Dentro del componente léxico analizado aquí, se aprecia que los procesos de mortandad experimentados por los indigenismos y los afronegrismos del español caribeño son muy similares en las tres islas. En todas el índice de mortandad ha sido muy alto $\mathrm{y}$ en términos absolutos es reducido el número de unidades léxicas conocidas y usadas por los hablantes de la zona. En la mayoria de las ocasiones los lexemas han desaparecido con la desaparición de las cosas mismas a las que hacían referencia. No se ha tratado, así, del desplazamiento de un elemento por otro llegado desde fuera, sino de una especie de muerte natural.

Ahora bien, cuando se consideran en sí mismas las unidades léxicas vi- 
gentes en cada una de las Antillas, se descubre que tanto los indigenismos como los afronegrismos funcionan como elementos dialectalmente diferenciadores de las islas del Caribe. Dentro de esa pequeña parcela, nuestro léxico compartido, al que podríamos llamar "panantillano", es notablemente inferior al privativo o exclusivo de cada país.

\section{Cundro 11}

Afronegrismos exclusivos de cada Antilla.

\begin{tabular}{|c|c|c|}
\hline Cuba & R. Dominicana & Puerto Rico \\
\hline 1. [de] ampanga & 1. burundanga & 1. anamú \\
\hline 2. bemba & 2. can & 2. bomba \\
\hline 3. biyaya & 3. cocolo & 3. candungo \\
\hline 4. cachimba & 4. concón & 4. cocolía \\
\hline 5. candangazo & 5. chininingo & 5. changa \\
\hline 6. congo & 6. desmandingarse & 6. chango \\
\hline 7. cumbancha & 7. féferes & 7. funche \\
\hline 8. cundango & 8. fua & 8. gongolf \\
\hline 9. cheche & 9. fucú & 9. monga \\
\hline 10. fufú & 10. furufa & 10. mongo \\
\hline 11. guaguancó & 11. macuto & 11. plátano mafafo \\
\hline 12. jelengue & 12. mandinga & \\
\hline 13. jubo & 13. mangú & \\
\hline 14 majá & 14. mangulina & \\
\hline 15. ñame 2 & 15. marimba & \\
\hline 16. ñinga & 16. mondongo & \\
\hline 17. quimbámbara & 17. musú & \\
\hline 18. quimbumbia & 18. กีeco & \\
\hline 19. sanaco & 19. กีeñeñé & \\
\hline 20. sirimba & 20. pachanga & \\
\hline 21. subuso & 21. sombi & \\
\hline 22. titingó & 22. taita & \\
\hline 23. tonga & 23. tutú & \\
\hline 24. yaya & 24. vodú & \\
\hline
\end{tabular}

En el nivel fonético también son significativas las diferencias cuantitativas, en cuanto a la frecuencia de aparición de determinados fenómenos, así como las cualitativas entre los dialectos de los respectivos países. Todo esto sin hacer referencia a la entonación, posiblemente el indicador de mayor fuerza discriminadora desde el punto de vista diatópico.

Por otra parte, sería interesante y revelador estudiar hasta qué punto son también distintos de una a otra de las Antillas los juicios evaluativos, las actitudes sociales de los hablantes que señalan como aceptables y prestigiosas unas formas y como estigmatizadas otras. De ser este el caso, como parece 
probable con respecto a ciertos fenómenos, estaríamos ante comunidades de habla diferentes, según la concepción de Labov ${ }^{25}$.

Tales observaciones plantean una interrogante que invita a reexaminar con nuevos y más amplios datos la tesis de la homogeneidad que tanto se ha proclamado para la región del Caribe Hispánico, una de las zonas dialectales consideradas más compactas por los investigadores que se han ocupado del tema de la zonificación dialectal del español en América.

Como se ha observado antes, el "español antillano" es una abstracción irrealizable, carente de hablantes reales. Y lo es por una doble razón. En primer lugar, por su misma condición "dialectal" ${ }^{26}$. En segundo lugar, porque no se trata de una modalidad lingüística única o de "un modo de hablar" único, como diría E. Coseriu. Más que un dialecto, el "español antillano" es un complejo dialectal, un macrosistema que contiene tres variedades diatópicas mayores: el cubano, el dominicano y el puertorriqueño. En el interior de cada una de ellas, a su vez, existen otras variedades diatópicas menores (sanjuanero, ponceño, etc.; cibaeño, capitaleño...) segmentadas o entrecruzadas por una red de modalidades diastráticas diferentes.

25 Para el conocido investigador, una comunidad de babla se define como un grupo de hablantes que comparten un conjunto de actitudes sociales hacia la lengua y no como un grupo que usa las mismas formas lingüísticas. (Cf. W. Labov, Sociolinguistic Patterns, Philadelphia, University of Pennsylvania Press, 1984, 10." ed., págs. 120-21, 158, 248n).

28 Véanse a este respecto las agudas consideraciones de López Morales, Sociolingüística, Madrid, Gredos, 1989, págs. 41. 